\title{
Experiências de captação de recursos e a interface com o marketing social: estudo de caso no Núcleo Social de Diadema
}

\author{
Experiences of fundraising and the interface with social marketing: a case study \\ in the Diadema Social Center
}

\section{Experiencias de recaudación de fondos y la interfaz con el marketing social: estudio de caso en el Núcleo Social de Diadema}

\author{
Alexandre Luzzi Las-Casas ${ }^{1}$ \\ Ruy Teske ${ }^{1}$ \\ Susana Costa e Silva ${ }^{2}$ \\ Belmiro do Nascimento João ${ }^{1}$
}

Recebido em 18/12/2019; revisado e aprovado em 17/07/2020; aceito em 28/12/2020

DOI: http://dx.doi.org/10.20435/inter.v22i2.2864

\begin{abstract}
Resumo: As organizações não governamentais (ONGs) são um dos tipos de organizações que compõem o terceiro setor. Este estudo tem o objetivo de identificar as estratégias para captação de recursos utilizada por uma ONG brasileira, verificar a interface com o marketing social e levantar oportunidades de aplicar estratégias para alavancar a captação de recursos. A pesquisa foi qualitativa, com o método de estudo de caso no Núcleo Social de Diadema. Como conclusões, foi possível avaliar vários pontos que fazem interface com o marketing. Os administradores devem procurar transpor as barreiras que existem nestes setores para a implantação da atividade e organizá-la, evitando dispersão de esforços. O planejamento estratégico deve ser aplicado pelas instituições do setor, bem como incluir uma adequada distribuição das diferentes fontes de recursos. Há uma tendência de centralização para a captação de recursos, o que limita a arrecadação. As estratégias de marketing se limitam à comunicação. No entanto há a diversificação de captação de recursos. Entre as várias conclusões apresentadas, percebe-se a necessidade de aplicação do marketing social na captação de doações para organizações com propostas sociais.
\end{abstract}

Palavras-chave: captação de recursos; terceiro setor; marketing social.

Abstract: Non-governmental organizations (NGOs) are one of the types of organizations that make up the third sector. This study aims to identify the fundraising strategies used by a Brazilian NGO, to verify the interface between fundraising and social marketing to apply strategies to leverage fundraising. The research was qualitative, using the case study method at the Diadema Social Center. As conclusions, it was possible to evaluate several points that interface with marketing. Managers must try to overcome the barriers that exist in these sectors for the activity implementation and organize it, avoiding dispersion of efforts. Strategic planning must be applied by the sector's institutions, as well as including an appropriate distribution of the different sources of funds. There is a tendency towards centralization for fundraising, which limits collection. Marketing strategies are limited to communication. However, there is diversification of fundraising. Among the various conclusions presented, there is a need to apply social marketing in attracting donations to organizations with social proposals.

Keywords: fundraising; third sector; social marketing.

Resumen: Las organizaciones no gubernamentales (ONGs) son uno de los tipos de organizaciones que conforman el tercer sector. Este estudio tiene como objetivo identificar las estrategias de recaudación de fondos utilizadas por una ONG brasileña, verificar la interfaz con el marketing social y generar oportunidades de aplicar estrategias para aprovechar la recaudación de fondos. La investigación fue cualitativa, utilizando el método de estudio de caso en el Núcleo Social de Diadema. Como conclusiones, fue posible evaluar varios puntos que interactúan con el marketing. Los administradores deben tratar de superar las barreras que existen en estos sectores para la implementación de la actividad y organizarla, evitando la dispersión de esfuerzos. La planificación estratégica debe ser aplicada por las instituciones del sector, además de incluir una adecuada distribución de las diferentes fuentes de fondos. Existe una tendencia a la centralización para la recaudación de fondos, lo que limita la recaudación. Las estrategias de marketing se limitan a la comunicación. Sin

\footnotetext{
${ }_{1}^{1}$ Pontifícia Universidade Católica de São Paulo (PUC-SP), São Paulo, São Paulo, Brasil.

${ }^{2}$ Católica Porto Business School, Porto, Portugal.
} 
embargo, existe una diversificación de la recaudación de fondos. Entre las diversas conclusiones presentadas, se destaca la necesidad de aplicar el marketing social en la captación de donaciones a organizaciones con propuestas sociales.

Palabras clave: recaudación de fondos; tercer sector; marketing social.

\section{INTRODUÇÃO}

Captação ou mobilização de recursos é um termo utilizado para descrever as diversas atividades de geração de recursos realizadas por organizações em apoio à sua principal finalidade. Segundo Speak, McBride e Shipley (2002), é o processo de geração de recursos das organizações sem fins lucrativos. A expressão "mobilização de recursos" atende melhor à conceituação que envolve o setor neste estudo. Desse modo, não significa apenas assegurar recursos novos ou adicionais, mas também aperfeiçoar os já existentes, conquistar novas parcerias e encontrar fontes alternativas de recursos financeiros.

Este estudo tem como objetivo a identificação das estratégias de captação de recursos utilizadas por uma ONG brasileira, verificar a interface estabelecida com as atividades de marketing social e levantar oportunidades para aplicação de estratégias neste domínio, no sentido de otimizar os resultados, os quais poderão servir como orientação para outras instituições do setor.

Uma das contribuições esperadas deste estudo é a avaliação dos procedimentos usados para esta captação e ponderar se estão adequadas às tendências do mercado. Pesquisadores têm explorado o tema de captação aplicado a diferentes setores (REARDON, 2014; MCCARTHY, 2017; MENG; JIUHONG, 2016; BAKER, 2016). Freitas (2004) abordou o financiamento e a captação de recursos de organizações não governamentais que trabalham com HIV/AIDS (Vírus da Imunodeficiência Humana/Acquired Immunodeficiency Syndrome) no Brasil. A autora concluiu que há um consenso da necessidade de se arrolarem diversos fatores, como a não interrupção de aportes do governo e a busca de diversificação de recursos.

De Andrade (2002) demonstrou que apenas 23\% das organizações pesquisadas aplicam estratégias sistematizadas de captação. Entre as recomendações, destacou-se o desenvolvimento de projetos continuados para a captação e parcerias.

Horochovski (2003) concluiu que mais da metade das instituições analisadas precisam do poder público para manter suas atividades, e, inclusive, um pouco mais de um quarto delas necessitam do estado para sobreviver. Não obstante pode-se afirmar que há, ainda, relativamente, poucos trabalhos na área que lidem especificamente com a captação de recursos para crianças carentes. Alguns deles focam em casos específicos de uma empresa ou região e mostram de que forma é que estas aplicam os conceitos e as técnicas propostas pelo marketing social na captação de recursos (FERRIMAN, 2011; HANLEY, 2015). Este estudo foca numa ONG com a função social de ajudar crianças carentes, tema ainda pouco explorado na captação de recursos, principalmente na abordagem de se avaliar a interdependência do marketing social.

Andreasen (1995) reformulou o conceito de marketing social, passando a sua orientação a ser mais feita para a mudança de comportamentos bons para a sociedade. Passou a ser visto como a aplicação das tecnologias do Marketing Comercial para a análise, planejamento, execução e avaliação de programas desenhados para influenciar o comportamento voluntário da audiência-alvo no sentido de melhorar seu bem-estar e o bem-estar da sociedade da qual ela é uma parte. A análise do marketing social contribuirá para a percepção e importância da prática 
mercadológica neste contexto, para o conhecimento de formas de captação de recursos, parcerias e possibilidade de implementar as sugestões. Por este motivo, a análise da aplicação de marketing social pela ONG estudada teve como foco a existência ou elaboração de um planejamento de marketing. Neste estudo, buscou-se fazer um diagnóstico das práticas de captação numa ONG e entender a interface da atividade de marketing da empresa com o marketing social. Esta verificação fornecerá informações relevantes neste estudo, que se propõe a ser exploratório, com a aplicação do método do estudo de caso.

\section{REVISÃO DE LITERATURA}

\subsection{Captação de recursos}

A National Society of Fundraising Executives (NSFRE) sugere alguns procedimentos para exercer uma atividade de captação de recursos, tais como: planejar, organizar a assessoria de desenvolvimento, conhecer profundamente a instituição, como sua missão, objetivos, programas específicos e necessidades. Além disso, sugere o desenvolvimento de políticas e procedimentos para a sistematização dessas atividades (ESTRAVIZ; CRUZ, 2003). Percebe-se o reforço frequente da aplicação de planejamento para a obtenção de recursos.

A captação de recursos deve ser vista como um negócio, pois, além de financiar o trabalho desenvolvido, ela promove a instituição. É essencial manter todas as informações arquivadas, sempre atualizando os dados dos doadores, o histórico de suas doações, as formas como as pessoas preferem colaborar, entre outros (CICCA, 2014).

Roesch (2002) aborda as relações em que os órgãos governamentais e as empresas figuram como fomentadoras das atividades das organizações do terceiro setor. O autor destaca que, além de obterem recursos pela provisão de serviços à população, é importante que as organizações atuem em parceria com o governo para receber recursos e, também, que explorem a filantropia corporativa tradicional. Disso decorre a primeira proposição:

P1: Parceria é chave para definir a captação de recursos. As empresas necessitam ser parceiras dos governos.

De acordo com Tenório (2004), para superar desafios que podem ameaçar a sua existência, as organizações do terceiro setor precisam pensar em acrescentar às suas peculiaridades novos instrumentos de gestão que melhorem sua capacidade de alcançar seus objetivos institucionais, como a aplicação das estratégicas administrativas e a recomendação de aplicação das técnicas de marketing para a obtenção de recursos, ou até mesmo como a colocação de Cicca (2014), que considera a atividade como um "negócio".

No processo de captação, a tendência é de que as organizações pequenas terceirizem a área por meio de consultores, e que as entidades maiores criem um departamento interno para tal finalidade (DIMENSTEIN, 2005). Portanto:

P2: A captação de recursos envolve todas as áreas de uma organização.

De acordo com a Asssociação Brasileira de Captadores de Recursos (ABCR, 2007), o captador deve ser transparente, ético, conhecer profundamente a instituição, a causa defendida, o mercado em que atua e no qual pretende atuar; deve planejar ações de marketing direto e social para a manutenção operacional da instituição e ser um profundo conhecedor da legislação vigente no país. Além disso, deve ser honesto em relação à intenção do doador, ter compromisso com a missão e a sustentabilidade da organização. 
Outros critérios são também essenciais para sucesso do negócio, como: paixão pela causa, sensibilidade, entusiasmo, persistência, paciência, dinâmica e muita criatividade. O captador é um profissional multidisciplinar, que precisa estar bem informado e ser articulador, facilitando os relacionamentos com os futuros doadores (DIMENSTEIN, 2005). Portanto:

P3: Devem existir profissionais especializados para exercer a função de captação.

Para captar ou mobilizar recursos de forma eficaz, especialistas do terceiro setor recomendam que as execuções dessas atividades envolvam aspectos estratégicos, tais como: análises de cenários, pesquisas das fontes de recursos existentes no mercado, planejamento de atividades e desenvolvimento de estratégias. As fontes de recursos podem ser empresas, fundações, pessoas, agências internacionais de financiamento, instituições locais, governo, venda de serviços e eventos. Portanto:

P4: Planejar e organizar é fundamental para o processo de captação de recursos. Devemse analisar cenários, fontes de recursos existentes e elaborar estratégias.

É preciso considerar que a saúde da organização exige que os recursos sejam captados de diferentes fontes e que nenhuma delas represente $60 \%$ ou mais da receita (CICCA, 2014). Um plano sólido é uma ferramenta essencial para o captador de recursos. Speak, McBride e Shipley (2002) afirmam que o objetivo de um plano de captação é desenvolver diretrizes para nortear as ações. A missão da organização é o ponto de partida para a construção do plano de captação - o que demonstra a sua importância. Acrescentam-se as proposições:

P5: Há necessidade de estabelecer missão, objetivos e programas específicos para diferentes tipos de doações e públicos.

P6: Deve haver políticas e procedimentos para sintetizar as atividades.

P7: Nenhuma fonte de recursos deve representar mais que $60 \%$ da receita.

Percebe-se que o processo de captação/mobilização de recursos é um dos principais desafios para a sustentabilidade de projetos. De acordo com Carvalho Filho (2004, p. 10), "sustentabilidade é um termo que podemos afirmar que tem muitos significados, mas é entendido aqui como a capacidade de captar recursos - financeiros e humanos - de maneira suficiente e continuada". Contudo pode-se afirmar que captação de recursos é uma atividade em que cada instituição trabalha com sua realidade, com suas demandas; cada projeto tem uma forma de captação de recursos.

As redes sociais são um elemento facilitador na captação de recursos e um importante aliado para aumentar a visibilidade e credibilidade das várias organizações. Por possuírem amplitude e concentração de forças, as redes têm um importante papel político no processo de transformação social. Portanto:

P8: As redes sociais são importantes facilitadores para a captação de recursos.

Entre as inúmeras dificuldades que as organizações encontram nesse processo, podemse citar a necessidade de apresentar expectativas, identificar as motivações e o interesse de ambas as partes e definir os objetivos comuns (DIMENSTEIN, 2005). A captação de recursos enfrenta dificuldades também na questão do apelo emocional. Outro importante fator é permitir que os doadores tenham oportunidade de se sentir como parte operacional do trabalho e saber o quanto seu envolvimento faz diferença no trabalho desenvolvido. A instituição precisa adotar várias estratégias para divulgar esses resultados entre os seus colaboradores, como informativos, boletins, cartas, eventos comunitários, entre outros. Isso necessariamente requer a disponibilização por parte dos recursos arrecadados (CICCA, 2014). 
P9: As empresas necessitam implantar novos instrumentos de comunicação que melhorem a capacidade de alcançar os objetivos institucionais.

\subsection{Marketing social e captação de recursos}

De acordo com Cicca (2014), antes do processo de captação de recursos, é importante realizar uma análise da organização para saber se ela está ou não pronta para desenvolver suas atividades no projeto. Neste processo, é fundamental examinar missão, visão e valores, para saber se a organização compreende quem ela é, por que existe e onde quer chegar. À medida que as entidades do terceiro setor profissionalizam sua gestão como condição essencial de sobrevivência, inevitavelmente são obrigadas a divulgar sua atuação de forma honesta e convincente, com vistas a ampliar seu leque de parceiros.

O termo de parceria é uma metodologia nova de relacionamento entre o poder público e a sociedade civil, um novo instrumento jurídico, criado pela Lei n. 9.790/99 para parcerias exclusivamente entre o poder público e as OSCIPs (Organização da Sociedade Civil de Interesse Público), com o objetivo de fomentar e executar projetos. As referidas hipóteses de transferências de recursos públicos necessitam de formalização por meio de instrumentos jurídicos próprios. Estes repasses podem ser feitos por intermédio de convênios, dos termos de parceria e dos contratos de gestão, bem como por meio de contratos de repasse, menos utilizados. As diretrizes teóricas com as proposições, fundamentação teórica e dimensão do estudo são apresentadas no Quadro 1. Diretrizes teóricas foram aplicadas em estudos anteriores (BARAKAT; BOAVENTURA; POLO, 2017).

Quadro 1 - Diretrizes teóricas do estudo

\begin{tabular}{|l|l|l|c|}
\hline \multicolumn{1}{|c|}{ Proposições } & \multicolumn{1}{|c|}{ Fontes } & \multicolumn{1}{c|}{ Marketing Social (interfaces) } & Dimensão \\
\hline $\begin{array}{l}\text { P1: Parceria é chave para } \\
\text { definir a captação de } \\
\text { recursos. As empresas } \\
\begin{array}{l}\text { necessitam ser parceiras } \\
\text { dos governos. }\end{array}\end{array}$ & $\begin{array}{l}\text { Estraviz e Cruz (2003); } \\
\text { Speak et al. (2002); } \\
\text { Cicca (2014); Drucker } \\
\text { (1994); Roesch (2002). }\end{array}$ & $\begin{array}{l}\text { Novos instrumentos de gestão. } \\
\text { Aplicação de estratégias } \\
\text { administrativas. Visão holística do } \\
\text { marketing social. Cocriação. }\end{array}$ & $1 ; 2$ \\
\hline $\begin{array}{l}\text { P2: A captação de } \\
\text { recursos envolve } \\
\text { todas as áreas de uma } \\
\text { organização. }\end{array}$ & $\begin{array}{l}\text { Falconer (1999); } \\
\text { Tenório (2004); Cicca } \\
\text { (2014); Dimenstein } \\
\text { (2014); ABCR (2007). }\end{array}$ & $\begin{array}{l}\text { A atividade é um “negócio". } \\
\text { Terceirização ou criação de } \\
\text { departamento de marketing social. } \\
\text { Marketing integrado. }\end{array}$ & $1 ; 2$ \\
\hline $\begin{array}{l}\text { P3: Devem existir } \\
\text { profissionais } \\
\text { especializados para } \\
\text { exercer a função de } \\
\text { captação. }\end{array}$ & $\begin{array}{l}\text { Dimenstein (2005); } \\
\text { ABCR (2007); Tenório } \\
\text { (2014). }\end{array}$ & $\begin{array}{l}\text { O captador deve ser transparente, } \\
\text { ético, conhecedor profundo da } \\
\text { instituição, da causa defendida, do } \\
\text { mercado no qual atua e no qual } \\
\text { pretende atuar; deve planejar ações } \\
\text { de marketing direto e social para a } \\
\text { manutenção operacional da instituição } \\
\text { e ser um profundo conhecedor da } \\
\text { legislação vigente no país. Todos } \\
\text { são pré-requisitos para a prática do } \\
\text { marketing social sustentável. }\end{array}$ & $1 ; 2$ \\
\hline
\end{tabular}




\begin{tabular}{|c|c|c|c|}
\hline Proposições & Fontes & Marketing Social (interfaces) & Dimensão \\
\hline $\begin{array}{l}\text { P4: Planejar e organizar } \\
\text { é fundamental para o } \\
\text { processo de captação } \\
\text { de recursos. Devem-se } \\
\text { analisar cenários, fontes } \\
\text { de recursos existentes e } \\
\text { elaborar estratégias. }\end{array}$ & $\begin{array}{l}\text { National Society of } \\
\text { Fundraising Executives } \\
\text { (NSFRE); Estravitz; Cruz } \\
\text { (2003). }\end{array}$ & $\begin{array}{l}\text { Planejamento e organização formam } \\
\text { a base de avaliação no processo de } \\
\text { marketing social. }\end{array}$ & $1 ; 2$ \\
\hline $\begin{array}{l}\text { P5: Há necessidade de } \\
\text { estabelecer missão, } \\
\text { objetivos e programas } \\
\text { específicos para } \\
\text { diferentes tipos de } \\
\text { doações e públicos. }\end{array}$ & $\begin{array}{l}\text { Cicca (2014); Speak, } \\
\text { McBride e Shipley } \\
\text { (2002). }\end{array}$ & $\begin{array}{l}\text { Segmentação na prática de marketing } \\
\text { social. Planejamento de marketing } \\
\text { estratégico social. }\end{array}$ & $1 ; 2$ \\
\hline $\begin{array}{l}\text { P6: Deve haver políticas } \\
\text { e procedimentos para } \\
\text { sintetizar as atividades. }\end{array}$ & $\begin{array}{l}\text { Cicca (2014); Speak, } \\
\text { McBride e Shipley } \\
\text { (2002). }\end{array}$ & $\begin{array}{l}\text { Plano tático e operacional do } \\
\text { planejamento no marketing social. }\end{array}$ & 2 \\
\hline $\begin{array}{l}\text { P7: Nenhuma fonte } \\
\text { de recursos deve } \\
\text { representar mais que } \\
60 \% \text { da receita. }\end{array}$ & $\begin{array}{l}\text { Cicca (2014); Speak, } \\
\text { McBride e Shipley } \\
\text { (2002). }\end{array}$ & $\begin{array}{l}\text { Métricas do marketing social, no caso } \\
\text { específico de captação. }\end{array}$ & 1 \\
\hline $\begin{array}{l}\text { P8: As redes sociais são } \\
\text { importantes facilitadores } \\
\text { para a captação de } \\
\text { recursos. }\end{array}$ & $\begin{array}{l}\text { Carvalho Filho (2004); } \\
\text { Dimenstein (2014). }\end{array}$ & $\begin{array}{l}\text { Marketing digital tende a ser aplicado } \\
\text { juntamente do marketing tradicional } \\
\text { para melhores resultados no âmbito } \\
\text { social. }\end{array}$ & $1 ; 2$ \\
\hline $\begin{array}{l}\text { P9: As empresas } \\
\text { necessitam implantar } \\
\text { novos instrumentos } \\
\text { de comunicação que } \\
\text { melhorem a capacidade } \\
\text { de alcançar os objetivos } \\
\text { institucionais. }\end{array}$ & $\begin{array}{l}\text { Dimenstein (2005); } \\
\text { Cicca (2014). }\end{array}$ & $\begin{array}{l}\text { Comunicação integrada de marketing } \\
\text { social com necessidade de feedback } \\
\text { para os receptores. }\end{array}$ & 2 \\
\hline
\end{tabular}

Nota: 1) Captação de Recursos; 2) Interface com o Marketing Social

Fonte: Elaborado pelos autores.

\section{METODOLOGIA}

Este estudo no Núcleo Social de Diadema (NSD) é de natureza exploratória, do tipo qualitativa, com o objetivo de verificar as estratégias de captação de recursos utilizadas e identificar a interface com o marketing social, assim como as oportunidades de aplicar estratégias de marketing para alavancar a captação de recursos. Malhotra (2005) afirma que, na pesquisa exploratória, o pesquisador consegue ampliar sua visão para melhorar a definição do problema de pesquisa e seus fatores subjacentes. A estratégia de pesquisa será o estudo de caso (YIN, 2005).

A confiabilidade e validade foram obtidas mediante pesquisa de diferentes fontes e entrevista com a diretora do NSD e outros colaboradores. Foi elaborado um protocolo do estudo de caso, permitindo a triangulação dos dados: análise das proposições, observação participante e resultado das entrevistas.

As entrevistas e a coleta de dados ocorreram no primeiro semestre de 2014 e em julho de 2017 (atualização do caso), seguindo um roteiro estruturado, no qual, segundo Gil (2002), 
esse tipo de entrevista segue uma relação fixa de perguntas, cuja ordem e redação permanecem invariáveis para todos os entrevistados. Foram realizadas entrevistas com perguntas abertas e respondidas por escrito. Foram utilizados também dados secundários fornecidos pelo NSD.

A ONG é reconhecida no mercado paulista como entidade social ética e que atua no mercado competitivo de captação de recursos. Adicionalmente, um dos pesquisadores é membro associado, o que permitiu a inserção na organização, algo recomendado na observação, que é uma das técnicas de coleta de dados de um estudo de caso (MARTINS, 2008). As informações foram fornecidas pela instituição, tanto em entrevista com a diretora (E1) quanto em processos virtuais. Além da entrevista com a diretora, foram entrevistados os seguintes profissionais: uma orientadora social (E2); um coordenador de projetos (E3); e um auxiliar administrativo (E4).

Algumas proposições foram elaboradas como construtos teóricos no que se refere à captação de recursos. Devido a sua importância nos resultados de uma captação, elas serão a base para a análise do caso estudado. Tais proposições, assim como o relatório, foram validadas com a apresentação e consulta a três especialistas da área que fizeram sugestões, as quais foram incorporadas na revisão do artigo. A validade ocorre quando se utilizam fontes múltiplas de evidências (YIN, 2005). A triangulação das informações é apresentada no Quadro 2. O formato da apresentação seguiu a ordem utilizada por outros autores (BARAKAT; BOAVENTURA; POLO, 2017; MOLON DA SILVA; RUAS, 2016), forma recomendada para o método de estudo de casos (YIN, 2005; CRESWELL, 2010).

Quadro 2 - Triangulação das informações para análise do caso

\begin{tabular}{|c|c|c|}
\hline Proposições & O que a empresa faz & Entrevistas \\
\hline $\begin{array}{l}\text { P1: Parceria } \\
\text { é chave para } \\
\text { definir a captação } \\
\text { de recursos. } \\
\text { As empresas } \\
\text { necessitam ser } \\
\text { parceiras dos } \\
\text { governos. }\end{array}$ & $\begin{array}{l}\text { Foi constatado que a instituição } \\
\text { procura elaborar acordos, sendo um } \\
\text { dos principais aspectos a captação dos } \\
\text { recursos. }\end{array}$ & $\begin{array}{l}\text { Os governos realizam parcerias e } \\
\text { convênios para ampliar ou viabilizar } \\
\text { a execução de serviços que cabem } \\
\text { ao poder público. E1 citou que } \\
\text { há recursos em todas as esferas } \\
\text { de investimentos, em áreas como } \\
\text { saúde, cultura, assistência social, } \\
\text { entre outras. }\end{array}$ \\
\hline $\begin{array}{l}\mathrm{P} 2: \text { A captação de } \\
\text { recursos envolve } \\
\text { todas as áreas de } \\
\text { uma organização. }\end{array}$ & $\begin{array}{l}\text { A necessidade de um departamento } \\
\text { não é conclusiva para o sucesso de } \\
\text { um empreendimento, visto que o } \\
\text { envolvimento e a distribuição de } \\
\text { funções são mais importantes que uma } \\
\text { estrutura funcional específica. }\end{array}$ & $\begin{array}{l}\text { "A estruturação de um } \\
\text { planejamento para captação de } \\
\text { recursos é, atualmente, um dos } \\
\text { maiores desafios das organizações } \\
\text { sem fins lucrativos no Brasil" (E1). }\end{array}$ \\
\hline $\begin{array}{l}\text { P3: Devem existir } \\
\text { profissionais } \\
\text { especializados } \\
\text { para exercer } \\
\text { a função de } \\
\text { captação. }\end{array}$ & $\begin{array}{l}\text { A falta de uma equipe especializada } \\
\text { foi mencionada por E1, o que } \\
\text { está em conformidade com o que } \\
\text { foi mencionado por Dimenstein } \\
\text { (2014), cuja tendência é de que as } \\
\text { organizações terceirizem a área ou } \\
\text { criem departamentos especializados. } \\
\text { A estrutura da empresa poderia ter } \\
\text { uma equipe dedicada à captação de } \\
\text { recursos. }\end{array}$ & $\begin{array}{l}\text { "O maior desafio [...] é o de } \\
\text { conquistar novos apoiadores para } \\
\text { dar continuidade a programas } \\
\text { e projetos em execução sem } \\
\text { uma equipe que se dedique } \\
\text { exclusivamente à captação de } \\
\text { recursos" (E3). } \\
\text { "A maior dificuldade da instituição } \\
\text { é não ter uma pessoa dedicada à } \\
\text { captação de recursos" (E4). }\end{array}$ \\
\hline
\end{tabular}




\begin{tabular}{|c|c|c|}
\hline Proposições & O que a empresa faz & Entrevistas \\
\hline $\begin{array}{l}\text { P4: Planejar e } \\
\text { organizar são } \\
\text { fundamentais } \\
\text { para o processo } \\
\text { de captação de } \\
\text { recursos. Analisar } \\
\text { cenários, fontes de } \\
\text { recursos existentes } \\
\text { e elaborar } \\
\text { estratégias. }\end{array}$ & $\begin{array}{l}\text { Foi observado que, quanto a este } \\
\text { aspecto, a instituição não divulga } \\
\text { ou não executa um planejamento } \\
\text { estratégico. O NSD, no entanto, faz } \\
\text { planos de ação e conhece o mercado. }\end{array}$ & $\begin{array}{l}\text { O gestor é quem fica responsável } \\
\text { pelo planejamento financeiro } \\
\text { da instituição, mas o restante da } \\
\text { equipe, não. Um dos respondentes } \\
\text { afirmou: "Não tenho conhecimento } \\
\text { do plano estratégico para captação } \\
\text { de recursos". (E4). }\end{array}$ \\
\hline $\begin{array}{l}\text { P5: Há } \\
\text { necessidade } \\
\text { de estabelecer } \\
\text { missão, objetivos, } \\
\text { e programas } \\
\text { específicos para } \\
\text { diferentes tipos } \\
\text { de doações e } \\
\text { públicos. }\end{array}$ & $\begin{array}{l}\text { O NSD tem entrado em concorrências } \\
\text { nos chamamentos públicos e nos } \\
\text { editais das empresas e instituições para } \\
\text { o desenvolvimento de projetos anuais. } \\
\text { Programas específicos para diferentes } \\
\text { tipos de doações. }\end{array}$ & $\begin{array}{l}\text { A missão da empresa é "Resgatar } \\
\text { a dignidade de crianças e } \\
\text { adolescentes para uma nova } \\
\text { perspectiva de vida através de } \\
\text { atividades socioeducativas em } \\
\text { Diadema" (E1). }\end{array}$ \\
\hline $\begin{array}{l}\text { P6: Deve haver } \\
\text { políticas e } \\
\text { procedimentos } \\
\text { para sintetizar as } \\
\text { atividades. }\end{array}$ & $\begin{array}{l}\text { O planejamento financeiro é o mais } \\
\text { comum. }\end{array}$ & $\begin{array}{l}\text { "O orçamento anual é elaborado } \\
\text { pela análise do balanço e } \\
\text { balancete do ano anterior e o } \\
\text { planejamento da instituição, tendo } \\
\text { em vista a continuidade ou não } \\
\text { de determinados projetos e a } \\
\text { implantação de novos". (E1). }\end{array}$ \\
\hline $\begin{array}{l}\text { P7: Nenhuma } \\
\text { fonte de recursos } \\
\text { deve representar } \\
\text { mais que } 60 \% \text { da } \\
\text { receita. }\end{array}$ & $\begin{array}{l}\text { Acredita-se em uma variedade de } \\
\text { fontes, mas pessoas físicas (PF) } \\
\text { foram mencionadas pela maioria } \\
\text { dos respondentes. As pessoas } \\
\text { aderem melhor às campanhas ou } \\
\text { eventos pontuais como o Natal. Há } \\
\text { também aqueles que participam mais } \\
\text { ativamente em eventos com finalidades } \\
\text { beneficentes ou doações por meio } \\
\text { de incentivos fiscais. Já as PJ (Pessoas } \\
\text { Jurídicas) têm apoiado projetos que } \\
\text { apresentam algum vínculo com sua } \\
\text { missão ou causa. Esperam um retorno } \\
\text { pelo seu apoio. As empresas desejam } \\
\text { se apresentar para seus clientes } \\
\text { preocupados em causas sociais. } \\
\text { Os governos, por sua vez, realizam } \\
\text { parcerias ou convênios para ampliar ou } \\
\text { viabilizar a execução de serviços que } \\
\text { cabem ao poder público. }\end{array}$ & $\begin{array}{l}\text { "Acredito que em qualquer lugar } \\
\text { há oportunidades de captação } \\
\text { de recursos, como em empresas, } \\
\text { igrejas, governo, pessoas físicas". } \\
\text { (E2). }\end{array}$ \\
\hline
\end{tabular}




\begin{tabular}{|l|l|l|}
\hline \multicolumn{1}{|c|}{ Proposições } & \multicolumn{1}{|c|}{ O que a empresa faz } & \multicolumn{1}{c|}{ Entrevistas } \\
\hline $\begin{array}{l}\text { P8: As redes } \\
\text { sociais são } \\
\text { importantes } \\
\text { facilitadores para } \\
\text { a captação de } \\
\text { recursos. }\end{array}$ & $\begin{array}{l}\text { O NSD tem utilizado esta ferramenta, } \\
\text { pois, segundo foi observado no } \\
\text { local, a atividade é bem frequente e } \\
\text { Os usuários consideram uma forma } \\
\text { muito útil de contato devido a sua } \\
\text { praticidade. }\end{array}$ & $\begin{array}{l}\text { "Entre outras aços bem-sucedidas } \\
\text { desenvolvidas [...] ferramentas } \\
\text { web, e-mails, Facebook e outras } \\
\text { redes sociais - para a divulgação do } \\
\text { trabalho realizado -, acompanhar } \\
\text { editais das principais empresas, } \\
\text { contar com o apoio de voluntários } \\
\text { para a conquista de novos } \\
\text { apoiadores e acompanhar e } \\
\text { participar de chamamentos públicos } \\
\text { incentivos fiscais mostrou-se } \\
\text { bastante eficaz". (E1). }\end{array}$ \\
\hline $\begin{array}{l}\text { P9: As empresas } \\
\text { necessitam } \\
\text { implantar novos } \\
\text { instrumentos } \\
\text { de comunicação } \\
\text { que melhorem } \\
\text { a capacidade } \\
\text { de alcançar } \\
\text { os objetivos } \\
\text { institucionais. }\end{array}$ & $\begin{array}{l}\text { Como ações que deram resultados } \\
\text { positivos, a entrega de relatórios } \\
\text { periódicos aos parceiros e apoiadores } \\
\text { atuais teve repercussões favoráveis. }\end{array}$ & $\begin{array}{l}\text { Uma das campanhas de maior } \\
\text { sucesso foi a de datas especiais. } \\
\text { Algumas campanhas de } \\
\text { apadrinhamento estão sendo } \\
\text { implantadas com boas perspectivas } \\
\text { de sucesso (E4). }\end{array}$ \\
\hline
\end{tabular}

Fonte: Elaborado pelos autores.

\subsection{Estudo de caso}

\subsubsection{O Núcleo Social de Diadema}

É uma das unidades de serviço da Tabea (Sociedade Batista de Beneficência Tabea), instituição filantrópica com oito unidades no Sudeste e Sul do Brasil para atendimento de crianças, adolescentes, idosos e comunidades em situação de vulnerabilidade social. Sua finalidade são atividades de defesa de direitos sociais, obras assistenciais e filantrópicas, de forma a atender aos preceitos da Lei Orgânica da Assistência Social, aplicando integralmente suas receitas, recursos e resultado operacional na manutenção e no desenvolvimento dos objetivos institucionais no território nacional.

\subsubsection{Captação de recursos}

Atualmente, as fontes de recursos financeiros são distribuídas da seguinte forma (Núcleo Social de Diadema [NSD], documento interno): instituições internacionais (39\%); pessoas jurídicas (4\%); pessoas físicas (10\%); produtos e serviços (2\%); instituições nacionais (7\%); igrejas (6\%); convênios públicos (31\%) e outros (1\%). A captação por meio de instituições, como igrejas, empresas e pessoas físicas pode ser financeira, em bens ou serviços, ou até mesmo em serviço voluntário.

Quanto ao voluntariado, há voluntários regulares que atuam na instituição. Também há voluntários próprios para eventos ou ações específicas. Observamos falta de conhecimento das pessoas em relação à legislação que permite a doação mediante incentivos fiscais.

As PJ têm apoiado projetos específicos que apresentam algum vínculo com sua própria missão/causa. De modo geral, as PJ têm interesse em apresentar-se a seus consumidores como uma empresa que investe em causas sociais. O NSD recebe apoio financeiro da Europäische Baptistische Mission (EBM International), que se identificou com a causa desde a sua fundação. 
A prestação de contas é ponto essencial para a credibilidade da instituição junto aos doadores. Isso acontece ao informar e entregar relatórios periódicos aos parceiros e apoiadores atuais, utilizar as ferramentas web, como sites, e-mails, Facebook e outras redes sociais, acompanhar editais das principais empresas/instituições, contar com a ajuda de voluntários para a conquista de novos apoiadores, acompanhar e participar de convocações públicas e incentivos fiscais. O NSD apresenta anualmente um relatório com as principais ações e resultados para todos os apoiadores.

O principal problema e desafio da instituição na captação de recursos é conquistar e fidelizar novos apoiadores para dar continuidade a programas ou projetos em execução, sem uma equipe que se dedique exclusivamente à captação de recursos. No orçamento, o valor destinado à publicidade encontra-se diluído entre outros itens.

O orçamento anual baseia-se no exame do balanço/balancete do ano anterior e no planejamento da instituição, avaliando a continuidade ou não de determinados projetos e a implantação de novos planos. O orçamento é enviado à diretoria da Tabea para apreciação e aprovação. A elaboração de um plano para conquista de recursos é um dos maiores desafios das instituições do terceiro setor.

\section{RESULTADOS E DISCUSSÃO}

As proposições que apresentam consistências foram analisadas conjuntamente, a fim de evitar repetições. Os conceitos muitas vezes se interpõem, tornando a análise repetitiva em certos aspectos. Por isso, as proposições P2 e P7; P3 e P4; P6 e P9 foram agrupadas.

P1: Parceria é chave para definir a captação de recursos. As empresas necessitam ser parceiras dos governos.

As parcerias devem ser desenvolvidas para que haja uma sinergia de atividades operacionais. Bolsi (2006) afirma que acordos celebrados pelo poder público constituem uma forma de exigir maior eficiência e melhores resultados na transparência da gestão (OLIVEIRA, 2006).

Foi constatado que a instituição procura elaborar acordos, sendo que um dos principais aspectos é a captação dos recursos. E1 mencionou que os governos realizam parcerias e convênios para ampliar ou viabilizar a execução de serviços que cabem ao poder público. A instituição apresenta suas propostas e concorre nos editais para o desenvolvimento de projetos que estejam de acordo com as políticas públicas e os planos de ações municipais. Os convênios públicos representam 31\% das captações da instituição. Além dessas parcerias, existem apoios financeiros internacionais. E1 também citou que, recentemente, perderam o apoio de outra instituição internacional que passou a priorizar projetos na região nordeste do país. Paes (2004) expõe que as parcerias geralmente devem ser baseadas em adequação dos instrumentos e dos resultados. A troca de interesses e de objetivos de uma organização pode determinar mudança de rumos. Portanto, para uma organização manter uma doação, sua continuidade é importante. Conforme apontado por Falconer (1999), as entidades internacionais governamentais e multilaterais foram aquelas que iniciaram o conceito de terceiro setor no Brasil. Estas instituições investiam muito no país, mas, com o passar do tempo, deixaram de investir com a mesma intensidade, obrigando as organizações brasileiras a procurarem outras fontes. Uma das justificativas identificadas na revisão da literatura foi de que uma das causas da redução foi o aumento das organizações operando no país. 


\section{P2: A captação de recursos envolve todas as áreas de uma organização.}

P3: Devem existir profissionais especializados para exercer a função de captação.

Conforme mencionado na revisão bibliográfica, o processo de captação deve começar com a contratação de um profissional capacitado para desenvolver um plano e, inclusive, as empresas mais organizadas estão montando departamentos internos para essa captação. Quanto a este aspecto, E1 respondeu à pergunta dos principais desafios da organização da seguinte forma: " $O$ maior desafio de nossa organização é o de conquistar novos apoiadores para dar continuidade a programas e projetos em execução sem uma equipe que se dedique exclusivamente à captação de recursos". Portanto a falta de uma equipe especializada foi mencionada por E1, o que está em conformidade com o que foi citado por Dimenstein (2014): a tendência é de as organizações terceirizarem a área ou criarem departamentos especializados, a estrutura da empresa poderia ter uma equipe dedicada à captação de recursos.

E2 comentou que a maior dificuldade da instituição é não ter uma pessoa dedicada à captação de recursos, o que também foi mencionado por E3 e E4. Ao mesmo tempo que a falta de um profissional especializado é uma dificuldade, constitui-se também no maior desafio, que é o de conquistar um especialista para o cargo, conforme enfatizado por E2. Paralelamente, acredita-se que a necessidade de um departamento não é conclusiva para o sucesso de um empreendimento, visto que o envolvimento e a distribuição de funções na organização são mais importantes que uma estrutura funcional específica. O captador, sim, deve ter qualificações conforme proposto pela ABCR (2007).

P4: Planejar e organizar é fundamental para o processo de captação de recursos. Devemse analisar cenários, fontes de recursos existentes e elaborar estratégias.

P5: Há necessidade de estabelecer missão, objetivos e programas específicos para diferentes tipos de doações e públicos.

Estas duas proposições estão relacionadas aos objetivos estratégicos. A forma mais segura de tornar a captação de recursos uma atividade simples é fazer um planejamento. A maior parte dos empreendedores sociais tem uma tendência natural de concentrar seus esforços na prestação de serviços e acaba não conseguindo se dedicar às tarefas administrativas que, normalmente, são vistas como tediosas.

Além disso, as organizações sem fins lucrativos não possuem uma grande estrutura administrativa e, por isso, estão sempre sobrecarregadas com as atividades do dia a dia.

O mesmo ocorre com os bons projetos em que se desperdiçam oportunidades em diferentes tentativas e, como consequência, desmotivam seus parceiros. Foi observado que, quanto a este aspecto, a instituição não divulga, ou não efetiva, um planejamento estratégico. Os entrevistados sabem que o gestor é quem fica responsável pelo planejamento financeiro da instituição, mas, conforme um dos respondentes afirmou: "Não tenho conhecimento do plano estratégico para captação de recursos" (E4).

As ONGs precisam diversificar suas fontes de renda para não permanecerem financeiramente vulneráveis. A dificuldade desta área em gerar receitas próprias aumenta ainda mais sua necessidade de aperfeiçoar a captação e aplicação desses recursos. O planejamento do marketing social é considerado nos planos estratégicos empresariais. Portanto, para um planejamento, há necessidade de se considerar os pressupostos das proposições P3 e P4.

Cicca (2009) mencionou que, antes do processo de captação de recursos, deve-se analisar a organização para saber se ela está ou não pronta para desenvolver as atividades do projeto, 
o que nos remete à análise de cenários, conforme a P3. Ainda, de acordo com o autor, tornase fundamental a análise da missão, da visão e dos valores. Estes aspectoś são comentados na P5, devido à melhor adequação para o estabelecimento de práticas e políticas. Neste sentido, a organização aplica certos procedimentos, tais como um planejamento ligado à disponibilidade de recursos. A entrevistada E1 indicou que o orçamento anual é elaborado pela análise do balanço e balancete do ano anterior e o planejamento da instituição, tendo em vista a continuidade ou não de determinados projetos e a implantação de novos. Ainda, neste questionamento, E1 mencionou onde estão as maiores oportunidades para a captação de recursos:

Concorrer nos chamamentos públicos e nos editais das empresas e instituições tem sido, para nós, uma oportunidade para o desenvolvimento de projetos anuais. Além disso, nossa instituição tem como objetivo ampliar a captação com PF, onde entendemos haver uma grande possibilidade de crescimento. As PF, além de fazerem doações financeiras, podem doar através de incentivos fiscais e, quando se identificam com a causa da instituição, procuram conquistar outras pessoas, empresas ou instituições da qual façam parte. (E1).

Outro entrevistado mencionou: "Acredito que em qualquer lugar há oportunidades de captação de recursos, como em empresas, igrejas, governo, pessoas físicas" (E2). E3 apontou ainda que as maiores oportunidades estão nas pessoas físicas, igrejas, fundações como Volkswagen, Fiat, Banco do Brasil, bancos, governos e empresas. E4 citou que as maiores oportunidades para captação se encontram em oficinas de esporte e editais de chamamento público. Como se percebe, existe uma variedade de fontes, mas PF foram mencionadas pela maioria dos respondentes. Um estudo do Charity Navigator, em 2016, revelou que 71\% das doações provêm de doadores individuais que doam para uma variedade de causas, tais como: religião (33\%), educação (16\%), serviços humanitários (12\%), saúde (8\%) e benefícios sociais (7\%).

P6: Deve haver políticas e procedimentos para sintetizar as atividades.

A instituição necessita de políticas e procedimentos para elaborar suas estratégias. Conforme Speak, McBride e Shipley (2002), o objetivo de um plano de captação é desenvolver diretrizes para nortear as ações. A missão da organização é o ponto de partida - ferramenta essencial para a construção do plano de captação. Um marco inicial para este procedimento é o estabelecimento de missão e visão, bem como seus valores. Estas orientações, quando são passadas para os funcionários e colaboradores, permitem a manutenção de coerência nas atividades.

Speak, McBride e Shipley (2002) afirmam que um plano bem-sucedido deve ter alguns elementos essenciais, tais como: missão, objetivos, objetivos estratégicos, metas, custos e orçamento detalhado. Neste aspecto, o NSD atende, em parte, estas propostas. Apesar de existirem algumas destas atividades, não há um documento que formalize os planos, com análise do ambiente, pois, conforme Estraviz e Cruz (2003), a sistematização de atividades deve ser com foco no planejamento formal, em que as bases e diretrizes das atividades são detalhadas e ressaltadas. O NSD, no entanto, faz os planos de ação e conhece bem o mercado. Ao analisar as maiores dificuldades para a captação de recursos, reconhece o profissionalismo, a equipe qualificada, projetos desenvolvidos com seriedade, resultados mensuráveis, recursos financeiros e uma diretoria e conselhos engajados. Conforme E1: "A instituição não nasce com todos estes requisitos; pelo contrário, são conquistados dia a dia com trabalho, dedicação, erros e acertos".

P7: Nenhuma fonte de recursos deve representar mais que $60 \%$ da receita.

Conforme mencionado no estudo, as organizações do terceiro setor precisam formar uma base filantrópica privada, porém não devem permitir que esta seja a única fonte de sustento. 
Roesch (2002) sustenta que os órgãos governamentais e as empresas figurem como importantes fomentadores das atividades do terceiro setor. Por isso, é importante que as organizações atuem em parceria para receber recursos e/ou explorem a filantropia corporativa. As contribuições de organizações internacionais são importantes também, apesar de sua decrescente participação na contribuição de recursos. Foi mencionada por E1 a importância destes setores conforme citação mencionada na análise de P3 e P4.

Ao comentar sobre as diferentes fontes de recursos utilizadas pela instituição, a entrevistada comentou que as pessoas costumam aderir melhor às campanhas ou aos eventos pontuais como o Natal. Já as pessoas jurídicas têm apoiado projetos que apresentam algum vínculo com sua missão ou causa. As pessoas jurídicas sempre esperam um retorno pelo seu apoio. As empresas desejam se apresentar para seus clientes preocupados com causas sociais. Os governos, por sua vez, realizam parcerias ou convênios para ampliar ou viabilizar a execução de serviços que cabem ao poder público.

As principais doações são provenientes das instituições internacionais, seguidas de convênios públicos. Estes percentuais estão dentro dos limites, 39\% e 31\%, respectivamente. Conforme mencionado no desenvolvimento teórico, nenhuma fonte deve representar mais que $60 \%$ da receita. A entrevistada informou que as contribuições internacionais estão sendo reduzidas apesar de sua relevância nas contribuições da empresa. Percebe-se a necessidade de um esforço maior no sentido de aumentar a participação de grupos de interesse, como de empresas privadas que atualmente representam apenas $4 \%$.

P8: As redes sociais são importantes facilitadores para a captação de recursos.

P9: As empresas necessitam implantar novos instrumentos de comunicação que melhorem a capacidade de alcançar os objetivos institucionais.

Foi apontado no desenvolvimento teórico que as empresas precisam usar novos instrumentos de comunicação, uma vez que se pretende aumentar a capacidade de gerar recursos. Tenório (2004) propõe instrumentos de gestão baseados nas funções gerenciais clássicas, o que corrobora com Drucker (1994) e Cicca (2014) na recomendação de aplicação de técnicas de marketing, uma vez que a atividade é considerada um negócio. E1 expôs as principais ações que foram utilizadas para a captação de recursos. Como ações que deram resultados positivos, E1 informou que a entrega de relatórios periódicos aos parceiros e apoiadores atuais tiveram repercussões favoráveis. Esta foi uma das recomendações de Cicca (2014) ao mencionar que a instituição precisa adotar diversas estratégias para divulgar os resultados aos seus colaboradores, visando maior transparência. E3 mencionou que as campanhas de maior sucesso foram aquelas realizadas em datas especiais, e o auxiliar administrativo apontou que algumas campanhas de apadrinhamento estão sendo implantadas, com boas perspectivas de sucesso. A diversificação de campanhas praticadas pela instituição é uma forma recomendada para atuação de uma ONG (MITTAL, 2017).

Dimenstein (2014) coloca que as redes sociais são consideradas eficientes para a mobilização dos agentes sociais em ações coletivas, auxiliando o fortalecimento institucional das organizações. O NSD tem utilizado esta ferramenta, pois, segundo foi observado no local, a atividade é bem frequente, e os usuários consideram esta uma das formas mais úteis de contato devido a sua praticidade. As mídias sociais e a Internet são formas de agilizar os contatos e permitem sua expansão regional para a captação. E1 informou que, entre outras ações bemsucedidas desenvolvidas pela instituição, como utilizar ferramentas da Internet e das redes sociais, 
acompanhar editais das principais empresas, contar com o apoio de voluntários para a conquista de novos apoiadores, e acompanhar e participar de chamamentos públicos e incentivos fiscais, mostrou-se bastante eficaz. Percebe-se, portanto, que há um esforço de melhoria nos resultados por meio de novas práticas, de acordo com proposições P5 e P9. No entanto nem sempre estas novas práticas estão relacionadas a resultados positivos.

\section{CONSIDERAÇÕES FINAIS}

No que se refere ao objetivo geral, foi possível perceber que a elaboração de um planejamento para a prospecção de novos financiadores, parceiros e doadores é tarefa fundamental no sistema de captação de recursos. Uma prospecção bem-feita facilitará o trabalho de captação, direcionando as atividades da equipe para contatos com maior probabilidade de sucesso.

Não há, na instituição, pessoas que dedicam seu tempo para captar recursos. Assim, ao confrontar o referencial teórico com as ações do NSD, percebe-se que o NSD aplica os conceitos descritos, porém em uma escala inadequada. Desta forma, a atividade fica centrada na diretora, que divide seu tempo com as atividades administrativas. De fato, uma organização deve ter uma equipe para esta atividade, constituída por pessoas motivadas e preparadas para essa captação. Este aspecto foi apontado pela maioria dos entrevistados do estudo, mas pouco foi feito para melhorar esta situação.

Apesar dessa centralização, o NSD aprendeu a utilizar diversas ferramentas para a captação de recursos, financeiros ou não. Falta um plano de ação mais consistente para desenvolver os doadores, e as estratégias de marketing restringem-se à comunicação. Considerando a experiência com serviços de voluntários, uma opção seria ter estes voluntários com um perfil adequado e uma ampla rede de contatos para incrementar a captação de recursos. No entanto o NSD diversifica as estratégias para captação de recursos, mas com concentração na captação de recursos internacionais e do governo com pouca participação de outros colaboradores, o que não é recomendável. Não foi observada nenhuma objeção quanto à prática de marketing social. Os comentários não foram contrários à sua aplicação. Por que motivo foi mencionado por todos os entrevistados que a maior dificuldade da empresa é a falta de uma pessoa responsável pela captação? A prática recomendada por muitos autores é que todos se envolvam no processo, principalmente os gestores.

Quanto aos objetivos específicos, de analisar as estratégias utilizadas para a captação de recursos, verificou-se que houve diversificação de estratégias para a captação de recursos. A empresa procurou inovar certos procedimentos para $\mathrm{PF}$, como a utilização de ferramentas virtuais. A instituição concentra-se na captação, mas, ao mesmo tempo, cuida para que este foco não tire de sua atividade principal seu cunho social.

Observou-se que o planejamento da empresa é feito de forma limitada, focando mais em aspectos financeiros do que mercadológicos. Percebe-se que, pelas ações que mais deram resultados, os colaboradores possuem uma visão muito mais tática do que estratégica no planejamento. Ações imediatistas e adaptadas a datas especiais são predominantes. A visão tática e operacional justifica-se na captação de recursos, uma vez que se assemelha às atividades de vendas na prática mercadológica, pois se trata de prática relacionada a resultados imediatos e visivelmente avaliada. 
A aplicação do composto de marketing concentra-se na atividade de comunicação, não considerando a forma integrada das diferentes variáveis controláveis do marketing. Existem autores que consideram que a comunicação é mais importante que o marketing na captação de recursos (SHEPARD, 2017), mas, mesmo assim, a visão integrada é a mais adequada. A P5 demonstra que deve haver programas específicos para diferentes tipos de doações e públicos. Este aspecto deve ser observado pelas empresas em função do procedimento de segmentação. A empresa estudada não pratica segmentação adequando planos formais para cada um dos diferentes públicos, apesar de que, ao considerar os diferentes segmentos, atua de forma diferenciada na prática. Mittal (2017) sugere que os esforços devem ser segmentados de acordo com a motivação dos doadores. Esta divisão de segmentos, com base na motivação dos doadores a investirem, trata-se de uma boa forma de segmentação, que pode trazer mais resultados no desenvolvimento do composto. O que se observa é que os autores reconhecem os benefícios da aplicação de marketing na captação de recursos (MITTAL, 2017; STEIMER, 2017), apesar de alguns preferirem a comunicação (SHEPARD, 2017). O maior problema de interface, como o marketing social, constitui-se na falta de sua aplicação de forma integrada e de conhecimento da atividade.

Quanto ao composto de comunicação, a empresa aplica estratégias básicas, centradas em propaganda, porém com baixo impacto. Ainda, no que se refere ao marketing aplicado, o marketing de relacionamento. Este estudo corrobora com as evidências da análise em que as relações com os stakeholders são tímidas, sem explorar o seu potencial. Uma forma recomendada de desenvolver vínculos com clientes pode ser a prática da cocriação. Este procedimento envolve os consumidores com a prática mercadológica da empresa, participando mediante sugestões e ideias. Além do envolvimento constante, desenvolve um senso de pertencimento, o que é positivo para a motivação, principalmente visando à manutenção das doações (LAS CASAS, 2014).

Portanto, como conclusão deste estudo, as empresas não estão aplicando de forma adequada o marketing social. Apesar de aceitação em certos setores, não há profissionais especializados e, por isso, as empresas perdem oportunidades no mercado. A conscientização de todos os colaboradores de uma empresa na obtenção de resultados pode contribuir para uma conformidade em sua aplicação. A prática de segmentação, análise de mercado e identificação de oportunidades pode auxiliar para atingir melhores resultados. Pesquisa é uma atividade importante e aparentemente pouco utilizada para orientação de estratégias. Como foi possível perceber, há várias citações que fazem interface com o marketing. Os administradores devem procurar transpor as barreiras existentes nestes setores que não valorizam as práticas mercadológicas, pois acreditam que foge do foco social e envolvimento emocional das pessoas que atuam dentro e fora da organização. As seguintes sugestões são propostas para as empresas que atuam no terceiro setor.

Sugestões para as empresas do setor: criar um banco de dados para gerir os doadores (PF e PJ), não somente para solicitar doações, mas oferecendo algo em troca, como atenção aos dias especiais; aproveitar melhor as instalações da padaria (vinda da Alemanha e que produz diversos tipos de pães) e da marcenaria do local (muito bem equipada) para surpreender os doadores, enviando-Ihes produtos feitos pelo NSD; existem empresas especializadas em desenvolver projetos para captação de recursos, mas que costumam ficar com 10\% a 15\% do valor auferido. O ideal seria aproveitar o conceito de voluntariado ou fazer parcerias com escolas de administração para que os projetos tenham o formato adequado a seu objetivo; maior participação na mídia, procurando oportunidades para maior exposição; utilizar o conceito de cocriação para desenvolver novos 
projetos com a comunidade. No futuro, será interessante desenvolver um método para que isso se torne realidade, e trabalhar o benchmarking para identificar as melhores práticas aplicadas em outras instituições; a instituição já tem uma cultura financeira, com elaboração de orçamentos, ferramentas de controle e auditoria externa. É possível fazer o mesmo com o marketing, desenvolvendo um plano anual de marketing para sustentar este trabalho de inclusão social.

Sugestões de pesquisas para a academia: o estudo de caso tem suas limitações, já que, por ser conduzido em uma só organização, os resultados não podem ser generalizados. Contudo, ao analisar a literatura existente, com pesquisa de outros estudiosos sobre o assunto, complementados pela entrevista e observação, é possível estender algumas destas propostas para outras empresas, principalmente no que se refere à necessidade de planejamento para obtenção de resultados. No entanto é recomendável, para estudos futuros, pesquisa utilizando o método de levantamento, em que diferentes setores seriam estudados e as práticas institucionais apontadas. Também, estudos experimentais. Testar novas técnicas com análise de resultados antes e depois, com ou sem grupos de controle, poderia auxiliar na identificação de práticas mais recomendadas para a obtenção de objetivos específicos.

\section{REFERÊNCIAS}

ANDREASEN, A. R. Marketing social change: changing behavior to promote health, social development, and the environment. San Francisco: Jossey-Bass, 1995.

ASSOCIAÇÃO BRASILEIRA DE CAPTADORES DE RECURSOS [ABCR]. Código de ética. Captação, [s.l.], 2007. Disponível em: http://captacao.org/recursos/institucional/codigo-de-etica.html. Acesso em: 13 jan. 2014.

BAKER, A. Getting short-changed? The impact of outside money on district representation. Social Science Quarterly, Copenhagen, v. 97, n. 5, p. 1096-12, 2016.

BARAKAT, S.; BOAVENTURA, J.; POLO, E. Alinhamento estratégico de responsabilidade social corporativa: um estudo de caso no setor bancário brasileiro. REAd, v. 12, n. 1, p. 206-33, jan./abr. 2017.

BOLSI, A. Parceria entre Estado e OSCIP: uma abordagem social e jurídica à luz da legislação vigente. In: OLIVEIRA, Gustavo Henrique Justino (Org.). Desafios do terceiro setor: atualidades e perspectivas. Curitiba: Ordem dos Advogados do Brasil, 2006.

CARVALHO FILHO, J. S. Manual de Direito Administrativo. Rio de Janeiro: Lumen Juris, 2004.

CICCA, I. Captação de Recursos: fontes distintas exigem estratégias diferentes. Guiame, [s.l.], 2014. Disponível em: http//www.guiame.com.br/m5.asp?cod_noticia=254\&cod_pagina=1082. Acesso em: 1으 maio 2014.

CRESWELL, J. Projeto de pesquisa: métodos qualitativo, quantitativo e misto. 3. ed. Porto Alegre: Artmed, 2010.

DE ANDRADE, M. V. Organizações do terceiro setor: estratégias para captação de recursos junto às empresas privadas. 2002. Dissertação (Mestrado em Engenharia de Produção) - Universidade Federal de Santa Catarina, Florianópolis, SC, 2002.

DIMENSTEIN, G. Captação de recursos para ONGs depende de planejamento e dedicação. Folha Online, [s.I.], 2005. Disponível em: http://www1.folha.uol.com.br/folha/dimenstein/noticias/gd260405.htm. Acesso em: 1 fev. 2014. 
DRUCKER, P. Administração de organizações sem fins lucrativos. São Paulo: Pioneira, 1994.

ESTRAVIZ, M.; CRUZ, C. M. Captação de diferentes recursos para organizações sem fins lucrativos. 2. ed. São Paulo: Global, 2003.

FALCONER, A. P. A promessa do terceiro setor. 1999. Dissertação (Mestrado em Administração) Universidade de São Paulo, São Paulo, SP, 1999.

FERRIMAN, A. Edible house raises funds for children's hospital. British Medical Journal [s.l.], v. 342, p. d3603, 2011. Disponível em: https://www.bmj.com/content/342/bmj.d3603. Acesso em: 30 ago. 2021.

FREITAS, K. B. A captação de recursos orientada para a sustentabilidade financeira das ONG/AIDS. In: CÂMARA, Cristina. Sustentabilidade: aids e sociedade civil em debate. Brasília: Ministério da Saúde/ Secretaria de Vigilância em Saúde, 2004.

GIL, A. C. Métodos e técnicas de pesquisa social. São Paulo: Bookman, 2002.

HANLEY, D. Simon Shaheen helps UPA raise funds for Gaza Children (Music \& Arts). Washington Report on Middle East Affairs, Washington, v. 34, n. 8, p. 44-1, 2015.

HOROCHOVSKI, R. R. Associativismo civil e estado: um estudo sobre organizações não governamentais (ONGS) e sua dependência de recursos públicos. Em Tese, Florianópolis, v. 1, n. 1, p. 109-27, ago./dez. 2003.

LAS CASAS, Alexandre. Cocriação de valor: conectando a empresa com os consumidores através das redes sociais e ferramentas colaborativas. São Paulo: Atlas, 2014.

MALHOTRA, N. Introdução à pesquisa de marketing. São Paulo: Prentice Hall, 2005.

MARTINS, G. Estudo de caso: uma estratégia de pesquisa. 2. ed. São Paulo: Atlas, 2008.

MCCARTHY, C. Take the collaborative approach to fundraising for students' affairs. Student Affairs Today, Copenhagen, v. 20, n. 2, p. 1-3, 2017.

MENG, M.; JIUHONG, Y. Research on gray system and quantitative model about the fund raising ability to China Private Equity Fund. Journal of Shanghai University, Xanguai, v. 21, n. 3, p. 365-69, 2016.

MITTAL, Vikas. 5 ways nonprofits can engage donors. American Marketing Association [AMA], Chicago, 2017. Disponível em: https://www.ama.org/marketing-news/5-ways-nonprofits-can-engage-donors/. Acesso em: 30 ago. 2021.

MOLON DA SILVA, F.; RUAS, R. Competências coletivas: considerações acerca de sua formação e desenvolvimento. REAd, Porto Alegre, v. 22, n. 1, p. 252-78, jan./abr. 2016.

OLIVEIRA, D. P. R. Planejamento Estratégico: conceitos, metodologias, práticas. 22. ed. São Paulo: Atlas, 2006.

PAES, J. E. S. Fundações, associações e entidades de interesse social: aspectos jurídicos, administrativos, contábeis, trabalhistas e tributários. Brasília: Brasília Jurídica, 2004.

REARDON, S. Ice-bucket challenger. Nature, Londres, v. 516, n. 7531, p. 316-17, 2014.

ROESCH, S. M. A. Gestão de ONGs: rumo a uma agenda de pesquisas que contemple a sua diversidade. In: ENCONTRO DA ASSOCIAÇÃO NACIONAL DOS PROGRAMAS DE PÓS-GRADUAÇÃO EM ADMINISTRAÇÃO [ENANPAD], 26., 22-25 set. 2002, Salvador. Anais [...]. Salvador: ANPAD, 2002. 
SHEPARD, Julia. Public relations, marketing or fundraising: who is best at public engagement? Charity News, [s.l.], 2017. Disponível em: https://www.charityinfo.ca/articles/public-relations-marketing-or-fundraisingwho-is-best-at-engagement. Acesso em: 8 maio 2017.

SPEAK, A.; MCBRIDE, B.; SHIPLEY, K. Captação de recursos: da teoria à prática. Canadá: Graphbox Coran, 2002.

STEIMER, Sarah. Midsize firms leverage philanthropy. Marketingnews, Chicago, v. 51, n. 6, p. 16-18, 2017. Disponível em: https://issuu.com/molly.soat/docs/mn_july2017-Ir/18. Acesso em: 30 ago. 2021.

TENÓRIO, F. G. (Org.). Gestão de ONGs: principais funções gerenciais. 8. ed. Rio de Janeiro: Fundação Getúlio Vargas, 2004.

YIN, R. K. Estudo de caso: planejamento e métodos. 3. ed. Porto Alegre: Bookman, 2005.

\section{Sobre os autores:}

Alexandre Luzzi Las-Casas: Doutor em Administração pela Fundação Getúlio Vargas (FGV). Atualmente é professor titular do departamento de administração da Faculdade de Economia, Administração, Contábeis e Atuariais na Pontifícia Universidade Católica de São Paulo (FEA/ PUCSP). Coordenador do programa de estudos pós-graduados em Administração na PUCSP. E-mail: alascasas@terra.com.br, Orcid: http://orcid.org/0000-0003-2098-0969

Rui Teske (in memorian): Mestre em Administração pela Pontifícia Universidade Católica de São Paulo (PUCSP). E-mail: posadm@pucsp.br, Orcid: http://orcid.org/0000-0001-7837-3008

Susana Costa e Silva: Doutora em Marketing pela University College Dublin (UCD), Irlanda. Atualmente, é professora associada na Católica Porto Business School (CPBS) e professora adjunta visitante na University of Saint Joseph, China. É presentemente diretora do Mestrado em Marketing e do Mestrado em Gestão na CPBS. Membro do Board da European Marketing Academy Conference. E-mail: ssilva@ucp.pt, Orcid: http://orcid.org/0000-0001-7979-3944

Belmiro do Nascimento João: Doutor em Comunicação e Semiótica pela Pontifícia Universidade Católica de São Paulo (PUCSP). Atualmente é professor titular do departamento de administração da Faculdade de Economia, Administração, Contábeis e Atuariais (FEA) e do programa de estudos pós-graduados em Administração na PUCSP. E-mail: bjoao@pucsp.br, Orcid: http://orcid.org/0000-0002-7994-9934 